\title{
Myoma in Pregnancy and Cesarean Myomectomy: A Matter of Debate for a Long Time
}

Andrea Tinelli ${ }^{1,2^{*}}$

${ }^{1}$ International Translational Medicine and Biomodelling Research Group, Department of Applied Mathematics, Moscow Institute of Physics and Technology (State University) Moscow Region, Russia

${ }^{2}$ Department of Gynecology and Obstetrics, Division of Experimental Endoscopic Surgery, Imaging Minimally Invasive Therapy and Technology, Vito Fazzi Hospital, Lecce, 73100, Italy

Myomas are the most common benign tumor of the genital organs of women of childbearing age. In some women, fibroids are present for years without any symptoms and are discovered accidentally during a gynecological examination, while in others, myomas cause significant morbidity and can cause the need for multiple surgical procedures [1]. Moreover, compared to the past, the trend of delayed childbearing and the advances of modern techniques of assisted reproduction lead to a steady increase of pregnants with fibroids. In fact, the estimated incidence of myomas in pregnancy is $2-4 \%$ [2]. In fact, a high percentage of cesarean sections (CSs) in women with fibroids were noticed during the first half of the twentieth century and later studies confirmed this [3]. In the early 20th century, maternal mortality with CS was as high as $2 \%$. Victor Bonney (1872-1953), a fellow of the Royal College of Obstetricians and Gynaecologists, was brave to attempt a caesarean myomectomy (CM) at that time. Bonney performed a CS and removed six fibroids in a 30 -year-old nulliparous woman with "fibroids of the uterus, complicated by pregnancy". $\mathrm{He}$ also advocated trial of vaginal birth in these cases, referring to a mother who "safely passed through three subsequent pregnancies" with a uterine scar. Bonney warned of the risk of scar rupture, drawing attention to "faulty suturing or weak union on account of sepsis". Proud of his achievement, he subsequently presented the CM case at the Royal Society of Medicine [4]. Sill the new century, operations on the uterus during the CS, except for excision of pedunculated myomas, ware always traditionally discouraged. While the contraindication for uterine surgery stems mainly from the fear of causing uncontrolled and perfuse bleeding, that may lead to a severe anemia, puerperal infection and to an unwanted hysterectomy. Uterine fibroids have been associated with a $10 \%-40 \%$ obstetric complication rate and adverse obstetric outcomes and, for many years, myomectomy during CS was considered an intervention with high risk of intraoperative and postoperative complications, until hysterectomy [5]. The problem of myomas in pregnancy is rather common and, unfortunately, clinicians have to compare against it; for example, a myoma located in the LUS can cause dystocia or present as a tumor previa, resulting in CS. In such cases, and in order to deliver the baby, the obstetrician is faced with the emergency decision of making the incision through or near the myoma, removing it, or choosing the classical incision to deliver the baby while avoiding cutting through or near the myoma. Moreover, pregnancy induces profound anatomical and physiological changes, with uterine artery diameter doubles and a progressive increase in the uteroplacental blood flow [6]. For the excessive increase uterine blood, performing a CM has consistently been condemned and discouraged as a risky procedure. In cases of a pedunculated subserous fibroid attached to the uterus with a small pedicle, suturing and excision of the pedicle is easy. However, resection of intramural myoma during CS is inadvisable and contraindicated by most of the leading textbooks of obstetrics $[7,8]$, primarily because it may stimulate perfuse uncontrolled bleeding that could lead to hysterectomy. Furthermore, myomas will often undergo remarkable involution after delivery and may even become pedunculated, thus

\section{Publication History:}

Received: August 27, 2014

Accepted: October 27, 2014

Published: October 29, 2014

\section{Keywords:}

Myomas, Cesarean myomectomy, Pregnancy

making easier and safer a $\mathrm{CM}$, as a postpartum intervention than at the time of CS $[7,8]$. Furthermore, because of bizarre nuclear changes myomas resected during pregnancy were often confused with sarcoma, thus leading to unnecessary anxiety and fear [9].

In the medical literature revision, however, there are several preliminary data and lately larger studies indicating that performing a $\mathrm{CM}$ or even during pregnancy is probably a safer procedure than previously believed. In fact, recent medical literature, however, indicates that these procedures are probably feasible and reliable if correctly performed, as reported by Incebiyik et al. [10]. In their study, the smallest leiomyoma was $5 \mathrm{~cm}$, while the largest was $22 \mathrm{~cm}$ including the patient with $3.300 \mathrm{~cm}^{3}$ fibroid nodule, none of their cases was complicated during uterine repair, only two patients needed blood transfusion after CM. Authors emphasized the fact that a CM performed by an experienced obstetrician is a safe procedure in selected patients. The advantages of $\mathrm{CM}$ included the uterine growth more rapidly than fibroids during pregnancy, and for this reason, uterine incision during pregnancy is almost always smaller than in the non-pregnant uterus. Moreover, the pregnant uterus is more elastic and less fragile, making suture placement easier. In my experience, $\mathrm{CM}$ can be feasibly and safely performed by intracapsular method [5], and it did not show difference between intracapsular $\mathrm{CM}$ group and control group, in term of pre and post-operative hemoglobin values, mean change in hemoglobin values, incidence of intraoperative hemorrhage, frequency of blood transfusion and of post-operative fever. The only two parameters that affect negatively the group submitted to intracapsular $\mathrm{CM}$ are: the duration of operation and the length of hospital stay. Since obstetricians often confronted with fibroids while performing CS and face the dilemma of how they should be managed, considering the cost-benefit of my study, I can affirm that intracapsular CM [5] can be performed with some confidence, without affecting adversely the postoperative course

"Corresponding Author: Dr. Andrea Tinelli, International Translational Medicine and Biomodelling Research Group, Department of Applied Mathematics, Moscow Institute of Physics and Technology (State University) Moscow Region, Russia, Tel: +39/3392074078; Fax: +39/0832315763; E-mail: andrea.tinelli@unisalento.it

Citation: Tinelli A (2014) Myoma in Pregnancy and Cesarean Myomectomy: A Matter of Debate for a Long Time. Int J Gynecol Clin Pract 1: 104. doi: http:// dx.doi.org/10.15344/2394-4986/2014/104

Copyright: (c) 2014 Tinelli. This is an open-access article distributed under the terms of the Creative Commons Attribution License, which permits unrestricted use, distribution, and reproduction in any medium, provided the original author and source are credited. 
and clinical outcomes. Obviously, meticulous attention to gentle hemostasis, sharp pseudocapsule dissection, adequate approximation of the myometrium edges and all dead spaces to prevent hematoma formation, can further increase the safety of such procedure, without significant complications. Today caesareans are safe, even available on demand. Myomectomy at caesareans is a debated topic, and frequently $\mathrm{CM}$ is only carried out by senior surgeons. In light of the data described above $[5,10]$ and by Adesiyun et al. [11] and Song et al [12], CM is not associated with increased morbidity, synthesizing two operations in one. Moreover, CM avoids the risks of re-laparotomy and further anesthesia, reducing costs of re-hospitalizations, costs of re-operations and indirect costs of absence from work [5,10-12]. Nevertheless, all authors [5,10-12] agree on the need to continue clinical experience by increasing the number of patients to submit to $\mathrm{CM}$ and verifying the ability to run the intracapsular $\mathrm{CM}$ in a variety of clinical conditions.

\section{References}

1. Okolo S (2008) Incidence, aetiology and epidemiology of uterine fibroids. Best Pract Res Clin Obstet Gynaecol 22: 571-588.

2. Parker WH (2007) Etiology, symptomatology and diagnosis of uterine myomas. Fertil Steril 87: 725-736.

3. Somigliana E, Vercellini P, Daguati R, Pasin R, De Giorgi O, et al. (2007) Fibroids and female reproduction: a critical analysis of the evidence. Hum Reprod Update 13: 465-476.

4. Jauniaux E, Khan KS (2014) Caesarean myomectomy: Victor Bonney reports the first case in 1913. BJOG 121: 193.

5. Tinelli A, Malvasi A, Mynbaev OA, Barbera A, Perrone E, et al. (2014) The surgical outcome of intracapsular cesarean myomectomy. A match control study. J Matern Fetal Neonatal Med 27: 66-71.

6. Palmer SK, Zamudio S, Coffin C, ParkerS, Stamm E, et al. (1992) Quantitative estimation of human uterine artery blood flow and pelvic blood flow redistribution in pregnancy. Obstet Gynecol 80: 1000-1006.

7. Cunningham FG, Leveno KL, Bloom SL, Hauth JC, Gilstrap LC III, et al. (2005) editors. Abnormalities of the reproductive tract. In Williams Obstetrics, 22st edn, Mcgraw-Hill Medical Publishing Division.

8. Ludmir J, Stubblefield PG (2002) Surgical procedures in pregnancy. In Gabbe SG, Niebyl JR, Simpson JL editors. Gabbe: Obstetrics-Normal and problem pregnancies,4th edn, Churchill Livingstone Inc 613.

9. Levy G, Hill MJ, Beall S, Zarek SM, Segars JH, et al. (2012) Leiomyoma: genetics, assisted reproduction, pregnancy and therapeutic advances. $J$ Assist Reprod Genet 29: 703-712.

10. Incebiyik A, Hilali NG, Camuzcuoglu A, Vural M, Camuzcuoglu H (2014) Myomectomy during caesarean: a retrospective evaluation of 16 cases. Arch Gynecol Obstet 289: 569-573.

11. Adesiyun AG, Ojabo A, Durosinlorun-Mohammed A (2008) Fertility and obstetric outcome after caesarean myomectomy. J Obstet Gynaecol 28: 710-712.

12. Song D, Zhang W, Chames MC, Guo J (2013) Myomectomy during cesarean delivery. Int J Gynaecol Obstet 121: 208-213. 